\title{
Article
}

\section{Social tourism as a modest, yet sustainable, development strategy: policy recommendations for Greece}

Kakoudakis, Konstantinos and McCabe, Scott

Available at http://clok.uclan.ac.uk/26460/

Kakoudakis, Konstantinos and McCabe, Scott (2018) Social tourism as a modest, yet sustainable, development strategy: policy recommendations for Greece. Journal of Policy Research in Tourism, Leisure and Events, 10 (3). pp. 189-203. ISSN 1940-7963

It is advisable to refer to the publisher's version if you intend to cite from the work. http://dx.doi.org/10.1080/19407963.2018.1443938

For more information about UCLan's research in this area go to http://www.uclan.ac.uk/researchgroups/ and search for <name of research Group>.

For information about Research generally at UCLan please go to http://www.uclan.ac.uk/research/

All outputs in CLoK are protected by Intellectual Property Rights law, including Copyright law. Copyright, IPR and Moral Rights for the works on this site are retained by the individual authors and/or other copyright owners. Terms and conditions for use of this material are defined in the policies page.

\section{CLoK}

Central Lancashire online Knowledge www.clok.uclan.ac.uk

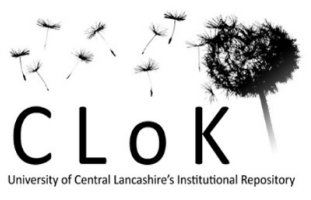




\title{
Social tourism as a modest, yet sustainable, development strategy: Policy recommendations for Greece
}

\begin{abstract}
Recent findings from social tourism research and evidence from its practice have shown that social tourism has multiple benefits, both for individual participants and host-communities within destinations. The latter in particular have been acknowledged by the European Union and have been included in its recent sustainable tourism policy. Yet, there are a limited number of studies that have attempted to explicate the close linkages between social tourism and sustainable development, and to inform public policy. This paper aims to do so with specific reference to Greek social tourism programmes. Drawing upon development theory, specifically sustainable development, and sustainable tourism research in particular, the study builds an argument for the potential of social tourism to act as a stabilising force in the Greek tourism system, contributing to the achievement of sustainability outcomes for host-communities. In doing so, the paper makes tangible policy recommendations, which are also timely, given the current socioeconomic environment that has been shaped in Greece, across Europe, and elsewhere, since the 2008 crisis.
\end{abstract}

Keywords: social tourism, sustainable development, seasonality, public policy, Greek crisis.

\section{Introduction}

Increasing evidence from the practice of social tourism programmes in continental Europe (e.g. Spain and Portugal) has shown that social tourism can contribute to the generation of 
employment and to the economic growth of host-communities that suffer from seasonality (e.g. Cisneros-Martínez, McCabe, \& Fernández-Morales, 2017; Eusébio, Carneiro, Kastenholz, \& Alvelos, 2013, 2016). These socioeconomic benefits have been acknowledged at the EU level, resulting in social tourism's recognition as an integral part of the EU tourism policy, with the potential to contribute to the achievement of sustainability outcomes for destinations (European Economic and Social Committee [EESC], 2006). On the other hand, in tourism research the concept of social tourism has been mainly studied in terms of the individual psychological benefits for social tourists (e.g. Kakoudakis, McCabe, S., \& Story, 2017; McCabe \& Johnson, 2013). Furthermore, within the sustainable tourism literature in particular, social tourism has been largely neglected. There are only a few studies that have focused on the specific relationship between social tourism and sustainability (e.g. Baumgartner, 2011; CisnerosMartínez, McCabe, \& Fernández-Morales, 2017).

As a consequence, existing tourism literature on the socioeconomic linkages between social tourism and sustainability, and the former's potential to contribute to the latter's objectives, remains scarce. This potential in conjunction with the cost-effectiveness of social tourism programmes (see Minnaert, Maitland, \& Miller, 2009) make the need for such studies urgent, especially in times of economic recession, following the Global Financial Crisis of 2008, social inequality, and major environmental concerns, phenomena that have taken extreme dimensions, threatening the quality of life of the present, and future, generations. This study attempts to addresses this gap in sustainable tourism literature by focusing on social tourism in Greece, a country that has suffered perhaps more than any other European country from the recent financial crisis and its consequences (Hellenic Statistical Authority [ELSTAT], 2016a). 
Tourism, as the main 'industry' of Greece, and thus a major agent of change, has been viewed as the vehicle towards development (Ministry of Economy, Development and Tourism, 2014). Indeed, tourism has been proved to be resilient during this critical period, contributing to a containment of the recession (Foundation for Economic and Industrial Research [IOBE], 2016). On the other hand, the prevailing model of mass tourism comes with major limitations (e.g. seasonality) (Buhalis, 2001), which do not allow tourism as it currently operates to bring about more positive and long-lasting changes in socioeconomic development. This paper argues that social tourism has the potential to address some of these limitations. Drawing upon development theory, specifically sustainable development, and sustainable tourism research in particular, the study builds an argument for the close relationship between social tourism and sustainability outcomes for host-communities at destinations in Greece. In doing so, and given that social tourism has been a neglected concept both in the Greek National Development agenda, and in tourism research in Greece, this paper also aims to stimulate future interest in social tourism amongst policy-makers and tourism scholars.

The paper proceeds with a brief critical review of the literature on sustainable development and tourism, which identifies the neglect of social tourism from these debates, and highlights its inherent linkages with sustainability. Then the current socioeconomic environment of Greece and the role of tourism within this environment are presented, to provide a context for the discussion on the limitations of Greek tourism as it currently operates, and the potential of social tourism to address some of these limitations, and to contribute to the country's socioeconomic stability, and sustainable development. The paper concludes with some tangible 
policy recommendations that are also transferable to other geographical contexts, with similar socioeconomic characteristics.

\section{Sustainable development and tourism}

While the concept of development had been traditionally defined in terms of economic growth, it has evolved over time, mainly due to the failures of political systems to incorporate human wellbeing (Goulet, 1992) and environmental concerns (Bramwell \& Lane, 1993) into their development agendas. This has resulted in the reconceptualisation of development towards a broader definition, which encompasses the multiple dimensions (e.g. economic, social, cultural, environmental, etc.) and complexities of social systems (e.g. poverty, social exclusion, unemployment, guaranteed human rights, and environmental protection), factors that also determine development (e.g. Sharpley, 2000). During this definitional and political shift, the Brundtland Report 'Our Common Future' (World Commission on Environment and Development [WCED], 1987) further contributed to the broadening of the development concept and agenda, by focusing on another parameter of, or requirement for, development, that is, sustainability. The Brundtland Report introduced sustainable development as a new paradigm of development, which 'meets the needs of the present without compromising the ability of future generations to meet their own needs' (WCED, 1987, p. 43). Since then, this new perspective of development has received significant attention in academic and policy circles, but in parallel, it has also been largely misconstrued.

'While sustainable development is intended to encompass three pillars, over the past 20 years it has often been compartmentalised as an environmental issue. Added to this, and 
potentially more limiting for the sustainable development agenda, is the reigning orientation of development as purely economic growth' (UN, 2010, p. 2). Today, and although misconceptions about the meaning and objectives of sustainable development still exist, it has become clearer that sustainable development reflects a holistic perspective of development, which means 'integrating the economic, social and environmental objectives of society, in order to maximise human well-being in the present without compromising the ability of future generations to meet their needs' (Organisation for Economic Co-operation and Development [OECD], 2001, p. 11). Indicative of this progress, and the increasing emphasis on human well-being, is the development of OECD's 'Better Life' Index (2011), which encompasses new and more holistic sustainable development approaches.

The popularisation of the sustainable development concept within tourism research, has led to the emergence of another concept, that is, sustainable tourism. Sustainable tourism has evolved in parallel with its parental concept, in the sense that it has also been largely misconstrued by tourism scholars. Until relatively recently, debates on sustainable tourism have reified environmental protectionism in the main in light of the climate-change lobby (Liu, 2003; Lu \& Nepal, 2009). This has meant an undue emphasis on environmental pillars at the expense of economic, and more importantly, sociocultural dimensions of sustainable development. Today, there has been an increasing recognition amongst tourism researchers that tourism operates within a broader economic, social and physical environment, and that sustainable development is a holistic concept that addresses all three aspects of this environment (McDonald, 2009). As a result, this wider perception of sustainability, and its social pillar in particular, has been addressed in several tourism studies on well-being and the quality of life of residents in host 
communities (e.g. Chi, Cai, \& Li, 2017; Kim, Uysal, \& Sirgy, 2013; Woo, Kim, \& Uysal, 2015). In line with these advancements in sustainable tourism research, it is imperative for tourism theory and practice to emphasise the potential of tourism to contribute to the well-being and quality of life of all actors involved. This paper argues that the role of social tourism can be pivotal towards this direction.

\section{Social tourism and sustainable development}

Social tourism mainly revolves around the inclusion of economically and socially disadvantaged populations in travel and tourism, through interventions (either policy or financial or other support) of a well-defined social nature (McCabe, Minnaert, \& Diekmann [eds], 2011). According to an increasing body of research, this inclusion holds a plethora of sociopsychological benefits for disadvantaged groups (e.g. Kakoudakis, McCabe, S., \& Story, 2017; McCabe \& Johnson, 2013; Minnaert et al., 2009; Morgan, Pritchard, \& Sedgley, 2015). These individual benefits in conjunction with the conceptual foundation of social tourism, may result in the public's perception that social tourism refers exclusively to welfare (e.g. AngloSaxon approach). However, evidence from the practice of social tourism in continental Europe (e.g. IMSERSO and INATEL social tourism programmes in Spain and Portugal, respectively) shows that social tourism simultaneously contributes to the generation of employment and to the economic growth of host-communities that suffer from seasonality (Cisneros-Martínez, McCabe, \& Fernández-Morales; 2107; Eusébio, Carneiro, Kastenholz, \& Alvelos, 2016).

Hence, in several countries, such as Spain, Portugal, Belgium, France, and Greece, it has become apparent that the provision of social tourism holidays is much more than welfare. Given 
the multiple benefits that emanate from its practice, it could be argued that, although the term 'social' hints towards philanthropy, social tourism benefits both individual tourists and the local economies at destinations. In actuality, social tourism fills in the gaps of general or mainstream tourism, namely, its inadequacy in encompassing neglected social groups, and areas in its framework. Moreover, it achieves this in a cost-effective way (Minnaert et al., 2009), while also adopting more environmentally sustainable practices. For instance, social tourism is mainly a domestic form of tourism (thus, resulting in lower carbon dioxide emissions), largely practiced during the off-season, and it often utilises more eco-friendly types of accommodation, such as hostels and caravans (see Baumgartner, 2011; Cisneros-Martínez, McCabe, \& FernándezMorales, 2017). In addition, the volume of social tourists is significantly lower than the volume of 'mainstream' tourists, which means that social tourism's impact on the carrying capacity of host-communities is rather minimal. Thus, social tourism contributes to several sustainable development indicators, such as public health, social inclusion, socioeconomic development, and sustainable transport (see Eurostat, 2013). As a result of these advantages, social tourism has begun to receive interest at an EU level, and has been viewed as a 'sustainable tourism structure' (EESC, 2006, point 2.4.3). Nevertheless, the emphasis of EU public policy has been on the economic dimension of sustainability (social tourism as a means to manage low-season).

Despite these strong linkages between social tourism and sustainability, within the large volume of sustainable tourism literature, social tourism remains under-researched. This is perhaps due to the fact that the debate on tourism and sustainability has primarily focused on environmental and economic issues, overshadowing socio-cultural ones (Cole, 2006). In one of the rather few studies that have discussed social tourism within the context of sustainability, 
Ryan (2002, p. 17) stresses that 'in addressing the issues of sustainability concepts akin to social tourism need to be applied.' In a similar vein, Higgins-Desbiolles (2006) has advocated the potential of social tourism to deliver various benefits to entire communities. This has been confirmed by recent studies on social tourism programmes in continental Europe. For instance, Eusébio et al. $(2013,2016)$ found that INATEL social tourism programme for seniors in Portugal had positive effects on local communities, not only in relation to the mitigation of seasonality, but also with regards to diversification and revitalisation of local economies. Similarly, findings from a study by Cisneros-Martínez et al., (2017) on the socioeconomic effects of IMSERSO social tourism programme in Spain show that social tourism is a very useful tool against seasonality, providing greater hotel occupancy in the low-season, which in turn has a positive impact on the wider local market, and can contribute to improved quality of life for residents in host communities.

The above effects are in addition to the positive effects on social tourists, which refer to the inclusion of disadvantaged social groups in tourism participation, and the positive impact of this participation in their quality of life. Hence, these multiple benefits simultaneously address important social and economic issues (e.g. unemployment and social exclusion), which have been persistent in several countries, and especially in those that still suffer from the adverse effects of the recent financial crisis, such as Greece. However, within the Greek tourism literature, and to the best of the authors' knowledge, there is only one conference paper that briefly discusses social tourism in relation to the socioeconomic dimensions of sustainability (see Despotaki, Tsartas, \& Doumi, 2015). This is a serious neglect, given the potential of social 
tourism to respond to some of the current social and economic issues that undermine Greece's sustainable development.

\section{The case of Greece: Tourism and the Greek development agenda}

Greece makes an interesting case to study these issues for three mains reasons: 1) its current socioeconomic environment is ideal in addressing some major global phenomena (e.g. unemployment, social exclusion, and acute poverty); 2) tourism has been a major agent of change in the country, and one of the few sectors that can contribute to its sustainable development (IOBE, 2016; Ministry of Economy, Development and Tourism, 2014); and 3) although social tourism has formed a part of Greek social policy since the 1980's, and support for its practice has been amongst the main Greek tourism policy targets (Buhalis, 2001; European Commission, 2014), yet it remains a particularly neglected area of study. Hence, Greece does not serve here as a geographical context, but as a socioeconomic context in which tourism plays a central role.

Greece is a country that has suffered severely from the recent financial crisis (ELSTAT, 2016a). Since the beginning of the recession, what has monopolised the rhetoric of the past two Administrations, the policy recommendations of the vast majority of economists, and the headlines of the Greek mass media, is the urgency for Foreign Direct Investment (FDI), which has been viewed as the 'key' to the country's economic recovery and development (Kathimerini, 2016a). This is in line with the tendency of governments worldwide to approach development from the economic growth perspective (Goulet, 1992). This approach, however, is often not consistent with the aims of sustainable development, including the achievement of long-term 
benefits for countries and their citizens (OECD, 2001). On the other hand, it could be argued that the focus of Greece on development strategies, such as FDI, has its underlying logic, given that the country has been with its back to the wall for seven consecutive years, and does not have many sectors with the potential to give the necessary boost to its economy.

Arguably, one of the few sectors which comprise the cornerstone of the Greek economy, and, hence, have the greatest potential to contribute to the country's development, is tourism. Greece has been a popular tourism destination, since the expansion of international mass tourism, mainly due to the attractiveness of its ancient history, climate, and natural environment (e.g. Buhalis, 2001). Tourism has a major contribution to Greece's GDP and employment rates, and it is often described as the 'barometer' of its economy. In 2015, for instance, the direct contribution of tourism is estimated at $9.8 \%$ of the GDP, and its total contribution (both direct and indirect) at 20-25\% (Association of Greek Tourism Enterprises [SETE], 2016). In the same period, tourism had also an important contribution to employment growth $(9.0 \%$ direct, and $18.9 \%$ total contribution) (SETE, 2016). Given the prolonged turbulence in the Greek economy, in the aftermath of a six-year recession, which has severely damaged sectors with a decisive impact on the country's economic and employment growth (e.g. constructions and services), the above figures confirm the resilience of the sector, and its significant contribution to a containment of the recession (IOBE, 2016).

On the other hand, it must be also acknowledged that the recent increase in international arrivals is, to a large extent, attributable to the political turmoil in the Middle East and North Africa, which has strengthened the attractiveness of Greece as a tourist destination. However, tourism demand is never constant, and therefore, destinations cannot take its growth for granted 
(Liu, 2003). Moreover, and despite this significant boost in its performance, tourism's contribution to the country's socioeconomic stability and sustainable development remains insufficient, especially when considering Greece's financial situation, unemployment rates, poverty, and the immense individual and social implications of these phenomena.

This is not to say that such complex socioeconomic issues is expected to be tackled through tourism alone, but rather to question whether tourism as it has been traditionally operated in Greece has reached its full potential to contribute to their mitigation. The answer is no, mainly due to four major limitations that Greek tourism has: a) from a tourism perspective, it suffers from seasonality; b) from an economic perspective, it is managed, to a large extent, by big businesses (e.g. tour-operators, and hotel-chains), which has resulted in the squeezing of small-medium enterprises (SMEs); c) from a social perspective, it largely excludes those most in need (e.g. low-income families, and unemployed individuals) from receiving the benefits of tourism participation (e.g. psychological benefits); and d) from an environmental perspective, the prevailing model of mass tourism has largely exploited the country's natural resources (e.g. Buhalis, 2001; ELSTAT, 2016b).

\section{What about the potential of social tourism?}

In Greece, social tourism is largely organised and run by public authorities. It was initiated in 1976 by the Greek National Tourism Organisation (EOT), and it was first launched in 1982 by EOT, the Worker's Social Benefits Organisation and the General Secretariat for Youth (Despotaki et al., 2015; European Commission, 2010a). Since then, social tourism programmes have benefited numerous citizens and businesses across the country. Nevertheless, its practice 
has seen significant fluctuations over time, both in terms of available budget, and volume of beneficiaries. This has been largely due to recurrent changes in public policies, and supply cuts. Indicative of these changes is that in 2012, social tourism programmes were cut down in line with the requirements of 'The Economic Adjustment Programme for Greece' to reduce public expenditure, a restructuring which had a significant negative impact on hospitality SMEs (Kathimerini, 2012). In midst of the financial crisis, social tourism received some new attention in the political discourse as a means to support the elderly in a period of pension and benefit cuts, and to boost the domestic market (Ministry of Economy, Development and Tourism, 2013). As a result of this attention, social tourism programmes were relaunched in 2013. In 2014, however, EOT's “Tourism for All” programme (including its sub-programme for seniors), the major social tourism programme in Greece, stopped running, and since then, it has been inoperative.

Currently, social tourism activity in Greece is mainly organised and run by the Manpower Employment Organisation (OAED), and the Agricultural Insurance Organisation (OGA), while also encompassing smaller private providers (e.g. 'KEMEN Hellas'). Public programmes operate all year round, and offer partially-funded holidays, through coupons (subsidies), to different target groups, namely, employed and unemployed individuals, seniors, people with disabilities, and their protected family members (the carers of people with a $67 \%$ disability or more, are also eligible to participate). The eligibility criteria vary to some extent, depending on each programme's provider; however, what all public programmes have in common, is that their beneficiaries live on low-income, and have not participated in any other social tourism programme over the past year. With regards to accommodation suppliers, all types of hotels, 
rooms to let, and campsites around Greece with a valid 'Special Operation Logo' are eligible to participate.

The duration of holidays, the number of beneficiaries, and the amount of subsidy differ amongst providers, and also fluctuate (to a larger or lesser extent) every year, depending on the amount of financing they receive from the Greek Government. For example, two recent publicly funded programmes run by OAED (2015) and OGA (2016), offered holidays (up to five overnight stays) to 150,000 and 55,000 beneficiaries, respectively. With regards to the amount of subsidy, in the period 2013-2014, for instance, OAED's programme subsidised 7,00€ to $22,00 €$ per person per night, depending on the chosen type of accommodation, whereas EOT's 20132014 programme subsidised $6,00 €$ to $14,00 €$ per person per night. For the same period OAED's budget was 10,000,000 € (OAED, 2013), and EOT's 5,000,000 €. (EOT, 2013). Although not constant, the minimum contribution of beneficiaries has been low (e.g. 1,00€ per person per night for EOT's programmes).

Recently, a new public initiative has been incorporated into the existing social tourism programmes run by OAED and OGA, aiming to boost the economic activity in the North Aegean Islands (e.g. Lesvos, Kos, Chios, Samos, and Leros), which have experienced a drop in tourist demand due to the refugee crisis in the region. These sub-programmes cover the full accommodation costs (up to ten overnight stays) for beneficiaries who will choose to one of the above destinations for their holidays (OAED, 2016).

This paper argues that social tourism can significantly contribute to the mitigation of some of the limitations of mass tourism, as it has the following attributes: a) it runs in the offseason period, aiming to extend the tourist flow beyond the summer-season; b) its services are 
largely provided by SMEs, the backbone of the Greek economy, which has been almost crashed during the recession; and c) its positive effects on people's physical and mental health benefit a large proportion of the population who has suffered the multiple consequence of this recession. Hence, social tourism addresses some of the major socioeconomic problems of Greece, such as unemployment, acute poverty, the shrinking of SMEs, and social exclusion (e.g. IOBE, 2016; Ministry of Economy, Development and Tourism, 2013), and in doing so, it is also consistent with the principles of sustainable development.

\section{Policy recommendations}

Considering the multiple benefits that emanate from the practice of social tourism, it is argued here that social tourism can play the role of the stabiliser of the Greek tourism system. It can create demand during the off-season period, enabling the continuity of tourist flow beyond the summer-season. In order to achieve this, some changes in the planning, implementation, and funding of social tourism are imperative. Social tourism programmes in Greece, run for a prolonged period of time throughout the year, offering beneficiaries the choice to go on holiday at any time during this period (e.g. between 15/10/2015 and 30/09/2016 for OAED's programme). The result of such a 'loose' implementation period is that social tourism practice fails to be specifically concentrated in the off-season period in Greece (November-April), when is mostly needed. Furthermore, Greece's budgetary limitations and new fiscal reforms, threaten the feasibility of publicly funded programmes in the long-term (Kathimerini, 2016b).

Arguably, the implementation period of social tourism programmes is necessary to be shortened. It is acknowledged that it is not feasible for social tourism to cover the whole six- 
month off-season period. Therefore, it is suggested that holiday-breaks should be offered only during the shoulder-season, thus extending the overall tourist season. This suggestion has three possible options, namely, to implement social tourism programmes: a) at the end of the tourist season; b) before the beginning of the new season; and c) both at the end of the tourist season and before the beginning of the new season. Although there is no right or wrong choice, implementing social tourism programmes before the beginning of the new season (e.g. March and April) combines several advantages. Firstly, it concerns the two months prior to the start of the summer-season, thus, aiming to contribute to an earlier start of the new tourist season; secondly, the tourism demand in this period is stronger than the respective demand recorded during November and December, therefore, an increase in overnight stays and other consumption will have a more sizable impact on the economy; and thirdly, the risk of non participation is lower, given that the weather in spring is better, and the Greek National Holiday and Easter Holidays (including a two-week school holiday) fall into this period of time.

Although the total number of social tourists in Greece per year is unknown due to the lack of available data, considering the latest press releases from OAED (2015) and OGA (2016), it is estimated that there are approximately 180,000 beneficiaries each year ${ }^{1}$. In reality, the total number is expected to be larger, given that there is also provision of social tourism holidays from private providers. With a maximum of five overnight stays that the publicly funded programmes

\footnotetext{
${ }^{1}$ OAED offered 150,000 beneficiaries the chance to go on a holiday between 15/10/2015 and 30/9/2016. OGA's programme runs between 23/7/2016 and 8/5/2017 and has 55,000 beneficiaries. In order to estimate how many beneficiaries in total went on a holiday in one year, we have set the time-frame of a year in line with the time-frame of OAED's programme (October-September). Then we added the total number of OAED's beneficiaries to the number of OGA's beneficiaries who went on a holiday until September 2016. Given that the latter figure is unknown, and considering the travel trend of Greeks to go on holidays mainly during the summer (ELSTAT, 2016a), it was assumed that the majority of OGA's beneficiaries went on holidays between July and September. The exact number of this majority is also unknown, and the choice of 30,000 beneficiaries serves as a rather conservative proxy to the true figure.
} 
offer each beneficiary, the total of overnight stays is approximately 900,000 per year. With a relatively even distribution of overnight stays in March and April, social tourism can contribute approximately 450,000 overnight stays to each of these months, strengthening a currently weak period of tourist demand, and contributing to a smoother transition from the off-season to the summer-season (Table 1).

[Table 1 near here]

In other words, it is argued here, that social tourism can act as an automatic stabiliser within the Greek tourism sector, and the local economies at destinations, helping increased consumption over a longer period of time, and, thus keeping local markets alive and in relative equilibrium (Keynes, 1997[1936]). Similarly to traditional automatic stabilisers, such as unemployment benefits, which cannot fully compensate for the consumption that is generated through the spending of the employed segment of the population, social tourism by no means can counterbalance the spending of international tourists. Its economic contribution is modest, yet, sustainable, given that low-income groups and their need for tourism participation will continue to exist in the future. In addition, the more stable economic activity that will be gradually generated, as a result of social tourism's demand, could offer a fruitful ground for the development of further economic activity both related and unrelated to tourism. For instance, a more stable economic environment within a region that suffers from seasonality could potentially strengthen the development of alternative forms of tourism (e.g. agritourism), and the creation of other SMEs which will respond to the increased demand for local products (e.g. agricultural), or 
lead to new international market demand. Indicative of these effects are findings from a recent study by Eusébio et al. (2016) on the impact of social tourism programmes at destinations in Portugal. The study found that social tourism for seniors had positive effects on local communities, not only in relation to the mitigation of seasonality, but also with regards to diversification and revitalisation of local economies.

On the other hand, budgetary limitations cannot be ignored since they comprise a major obstacle for the sustainability of social tourism programmes in Greece. Therefore, estimating the costs and potential returns of social tourism practice is imperative both for policy-makers and the public opinion (e.g. tax-payers). The 'Social Tourism 2015-2016' programme, for instance, had a 10 million $€$ budget (OAED, 2015). Although there are no available data in order to estimate the tax revenue for the State as a result of the economic activity that social tourism has generated, data from similar initiatives abroad, show that it is significant. For example, the Spanish State has received (or recovered) $1.32 €$ in taxes (e.g. VAT) and other savings (e.g. social protection) for every euro invested in the pilot transnational programme 'Europe Senior Tourism' (European Commission, 2010b). Furthermore, given that in Greece the maximum amount of contribution, per beneficiary per night, is $5 €$ on average, there is a maximum spending of 3.75 million $€$ for accommodation only (OAED, 2015). With additional per person spending on food, drink and activities to be taken into consideration, it could be argued that with a modest public investment, social tourism generates important economic benefits both for the State and the local markets at destinations. In addition, social tourism helps SMEs (the cornerstone of the Greek private sector, which has almost collapsed as a result of the deep economic recession) to survive at the present, 
and grow in the future. Yet, a major obstacle in the case of Greece is the extent to which the State can implement a functional tax-system.

Given these potential financial returns, it is suggested that a smoother transition from the off-season to the summer-season could be further assisted by an increase in the number of social tourists. Admittedly, the current number of beneficiaries is particularly low given the socioeconomic characteristics of a large proportion of the Greek population. According to the latest available data, in $2015,35.7 \%$ of the population lived at risk of poverty or social exclusion, and $40.7 \%$ of the population experienced material deprivation, including the inability to afford a one-week holiday every year (ELSTAT, 2016a). This means that the beneficiaries of publicly funded social tourism holidays account only for the $3.5 \%$ of the population living at risk of poverty or social exclusion, and the $3.1 \%$ of those experiencing material deprivation ${ }^{2}$. Hence, if Greece wants to utilise social tourism's potential more fully, it needs to increase (at least gradually) the proportion of individual beneficiaries, through additional public or public-private funding. This increase will result in a more sizable contribution to the country's sustainable development goals, such as further reduction of social exclusion, increase of citizens' (both social tourists' and residents' of host-communities) well-being and quality of life, and will further boost the economic activity and employment rates at destinations. Recent research on INATEL and IMSERSO social tourism programmes in Portugal and Spain, respectively, confirms this potential (see Cisneros-Martínez, McCabe, \& Fernández-Morales, 2017; Eusébio et al., 2013, 2016). Although it is acknowledged that any increase in tourist flow can potentially have negative environmental effects, this is highly unlikely in the case of social tourism for several reasons. For instance, social tourism largely concerns a domestic form of tourism, which

\footnotetext{
${ }^{2}$ Estimations according to the 2011 Population - Housing Census revision of 20/3/2014 (ELSTAT, 2014).
} 
adopts environmentally conscious practices (e.g. use of public transport and more eco-friendly accommodation), and is practiced in neglected areas during the off-season (see Baumgartner, 2011; Cisneros-Martínez et al., 2017). Moreover, the volume of social tourists is significantly lower than the volume of 'mainstream' tourists, and it can always be controlled by the public authorities which are the main providers of social tourism programmes.

These recommendations do not imply that social tourism can stand alone. Hence, it must not be misconstrued as a single strategy that operates independently from mass tourism, other forms of tourism, and other sectors. In contrast, it is suggested here that social tourism should be fully integrated both into the tourism, and the wider socioeconomic, system of Greece. With regards to the former, tourism can act as the means that ensures the continuum of tourist flow for a prolonged period of time, thus playing the role of a successive and complementary strategic tool to mass and alternative forms of tourism. Within this equation, social tourism can assist the sustainability of the tourism sector as a whole. For instance, after the end of the off-season period, the tourism system will continue to operate as usual, mainly through international arrivals, but it will do so under different conditions than before. SMEs will be in a more favourable position in terms of revenues and liquidity ability, which will allow them to better compete. In turn, this will result in a more fair competition between large businesses and SMEs, thus, reducing the inequality of opportunities and prospects within the private sector, and contributing to the sustainability of SMEs. Finally, within a more stable and fair economic environment, any unsustainable practices, which are often encouraged by financial strain (e.g. tax-evasion) are more likely to fade (Bramwell, 1998). 


\section{Conclusions}

This paper has discussed the potential of social tourism to contribute to sustainability outcomes for host-communities at destinations, by focusing on the case of Greece. After highlighting the strong conceptual linkages between social tourism and sustainable development, and the limitations of Greek tourism as it has been traditionally operated, the paper identified that social tourism can address some of these limitations, and in doing so, it does offer potential to mitigate against the major socioeconomic problems (e.g. unemployment, acute poverty, and social exclusion) which have overwhelmed Greece since the beginning of the recent financial crisis. This potential of social tourism has not been realised as yet however, mainly due to the lack of proper planning and implementation of social tourism programmes, and the vulnerability of social tourism to cuts in public expenditure. Therefore, the paper has proposed some tangible policy recommendations with the aim to unleash this potential. Specifically, we suggested that social tourism programmes should run exclusively during the shoulder-season in order to contribute to the extension of the tourist season, and by doing so, stabilise the socioeconomic situation in tourism communities at destinations. In addition, we stressed the need for an increase in the number of social tourists through public or public-private partnership funding. If this were to happen, social tourism could address both tourism-specific and wider societal issues (e.g. Eusébio et al., 2016), all of which impede the country's sustainable development. This contribution may be modest, but it is expected to bring about positive, long-term effects.

On the other hand, it must be acknowledged that the conceptual character of this paper imposes certain limitations. Given the absence of empirical data, the economic benefits of social tourism have been presented as simple approximations. Similarly, any wider social benefits have 
not been empirically explored. Hence, there is a need for empirical studies that will measure the specific economic benefits of social tourism for host-communities, and will explore the wider social impact of these benefits. Furthermore, in spite of the very diverse range of social tourism programmes and systems in Europe (McCabe, Minnaert, \& Diekmann [eds], 2011), an attempt to compare findings from different cultural contexts would have possibly strengthened our policy recommendations. Finally, the focus of this paper on Greece's socioeconomic environment has resulted in de-emphasising the environmental pillar of sustainable development. Although the environmental pillar maybe the less sustainable in social tourism in relation to the economic and social pillars, future studies on the potential environmental effects of social tourism programmes on host communities are needed to help us better understand the relationship between social tourism and all three pillars of sustainable development.

\section{References}

Baumgartner, C. (2011). Social tourism and sustainability. In S. McCabe, L. Minnaert, L., \& A. Diekmann (Eds.), Social tourism in Europe: Theory and practice (pp. 166-177), Bristol: Channel View.

Bramwell, B. (1998). Selecting policy instruments for sustainable tourism. In W.F. Theobald (Ed.), Global Tourism (pp. 361-379). Oxford: Butterworth-Heinemann.

Bramwell, B., \& Lane, B. (1993). Sustainable tourism: An evolving global approach. Journal of Sustainable Tourism, 1 (1), 1-5.

Buhalis, D. (2001). Tourism in Greece: Strategic analysis and challenges. Current Issues in Tourism, 4 (5), 440-480. 
Cisneros-Martínez, J. D., McCabe, S., \& Fernández-Morales, A. (2017). The contribution of social tourism to sustainable tourism: a case study of seasonally adjusted programmes in Spain. Journal of Sustainable $\quad$ Tourism, $\quad$ Retrieved from http://dx.doi.org/10.1080/09669582.2017.1319844

Chi, C. G., Cai, R., \& Li, Y. (2017). Factors influencing residents' subjective well-being at World Heritage Sites. Tourism Management, 63, 209-222.

Cole, S. (2006). Information and empowerment: The keys to achieving sustainable tourism. Journal of Sustainable Tourism, 14 (6), 629-644.

Despotaki, G., Tsartas, P., \& Doumi, M. (2015, October). Social tourism as a breath of the crisis in Greece: Research on social tourism institutions. Paper presented at the $1^{\text {st }}$ International Conference on Experiential Tourism, Santorini, Greece.

EESC (2006). Opinion of the European Economic and Social Committee on Social tourism in Europe. $\quad$ Retrieved from http://eur-lex.europa.eu/legalcontent/EN/TXT/?uri=CELEX\%3A52006IE1155

ELSTAT (2014). 2011 Population and housing Census - Housing Census revision of 20/3/2014. Retrieved from http://www.statistics.gr/en/statistics/-/publication/SAM03/-

ELSTAT (2016a). Greece in figures: October-December 2016. Retrieved from http://www.statistics.gr/en/greece-in-figures

ELSTAT (2016b). Arrivals and nights spent in hotels, similar establishments and tourist campsites: 2015. Retrieved from http://www.statistics.gr/en/statistics/-/publication/STO12/2015 


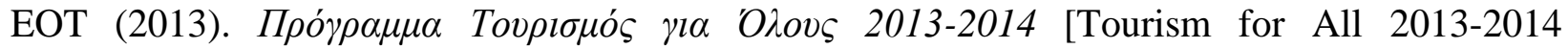
Programme]. Retrieved from http://www.koinonikostourismos.gr/pdfs/tourgiaolous2013_2014.pdf European Commission (2010a). Calypso study on social tourism: Greece. Retrieved from http://ec.europa.eu/DocsRoom/documents/6936?locale=en

European Commission (2010b). Calypso study on social tourism: Spain. Retrieved from http://ec.europa.eu/DocsRoom/documents/6948?locale=en

European Commission (2014). Annual Tourism Report 2013 - Greece. Retrieved from http://ec.europa.eu/DocsRoom/documents/5957/

Eurostat (2013). Sustainable development indicators. Retrieved from http://ec.europa.eu/eurostat/web/sdi/indicators

Eusébio, C., Carneiro, M. J., Kastenholz, E., \& Alvelos, H. (2013). The economic impact of health tourism programmes. In A. Matias, P. Nijkamp, \& M. Sarmento (Eds.), Quantitative Methods in Tourism Economics (pp. 153-173), Heidelberg: Physica.

Eusébio, C., Carneiro, M. J., Kastenholz, E., \& Alvelos, H. (2016). The impact of social tourism for seniors on the economic development of tourism destinations. European Journal of Tourism Research, 12, 5-24.

Goulet, D. (1992). Development: Creator and destroyer of values. World Development, 20 (3), $467-475$.

Higgins-Desbiolles, F. (2006). More than an "industry": The forgotten power of tourism as a social force. Tourism Management, 27 (6), 1192-1208. 
IOBE (2016). The Greek economy (No. 82). Retrieved from http://iobe.gr/docs/economy/en/ECO_O4_15_REP_ENG.pdf

Kakoudakis, K. I., McCabe, S., \& Story, V. (2017). Social tourism and self-efficacy: Exploring links between tourism participation, job-seeking and unemployment. Annals of Tourism Research, 65, 108-121.

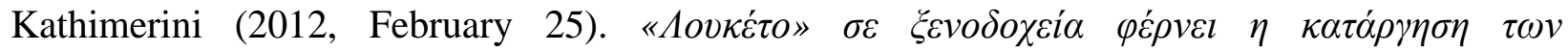

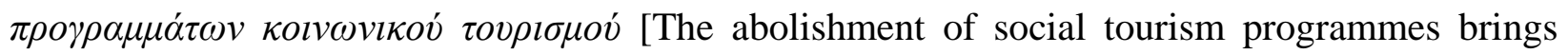
$\begin{array}{llll}\text { hotel } & \text { shutdowns]. } & \text { Retrieved } & \text { from }\end{array}$ http://www.kathimerini.gr/451515/article/oikonomia/epixeirhseis/loyketo-se-3enodoxeia-ferneih-katarghsh-twn-programmatwn-koinwnikoy-toyrismoy

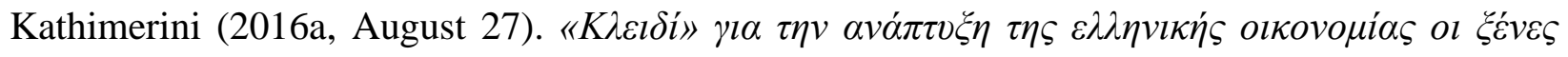
$\varepsilon \pi \varepsilon v \delta \dot{v} \sigma \varepsilon l \varsigma$ [Foreign investments, 'key' for the development of the Greek economy]. Retrieved from http://www.kathimerini.gr/872418/article/oikonomia/ellhnikh-oikonomia/kleidi-gia-thnanapty3h-ths-ellhnikhs-oikonomias-oi-3enes-ependyseis

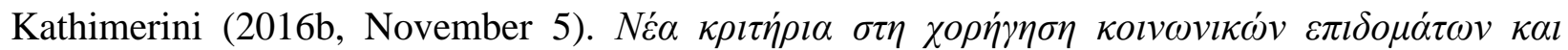

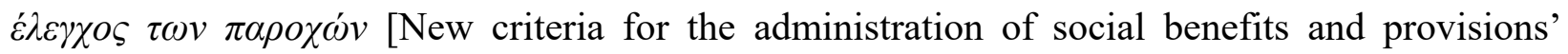
control]. Retrieved from http://www.kathimerini.gr/882206/article/oikonomia/ellhnikhoikonomia/nea-krithria-sth-xorhghsh-koinwnikwn-epidomatwn-kai-elegxos-twn-paroxwn

Keynes, J. M. (1997). The general theory of employment, interest, and money. New York, NY: Prometheus Books (Originally published 1936).

Kim, K., Uysal, M. \& Sirgy, M. J. (2013). How does tourism in a community impact the quality of life of community residents? Tourism Management, 36, 527-540. 
Liu, Z. (2003). Sustainable tourism development: A critique. Journal of Sustainable Tourism, 11 $(6), 459-475$.

Lu, J., \& Nepal, S. K. (2009). Sustainable tourism research: An analysis of papers published in the Journal of Sustainable Tourism. Journal of Sustainable Tourism, 17 (1), 5-16.

McCabe, S., \& Johnson, S. (2013). The happiness factor in tourism: Subjective well-being and social tourism. Annals of Tourism Research, 41, 42-65.

McCabe, S., Minnaert, L., \& Diekmann, A. (Eds.). (2011). Social tourism in Europe: Theory and practice. Bristol: Channel View.

McDonald, J. R. (2009). Complexity science: An alternative worldview for understanding sustainable tourism development. Journal of Sustainable Tourism, 17 (4), 455-471.

Minnaert, L., Maitland, R., \& Miller, G. (2009). Tourism and social policy: The value of social tourism. Annals of Tourism Research, 36 (2), 316-334.

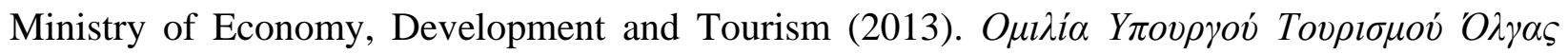

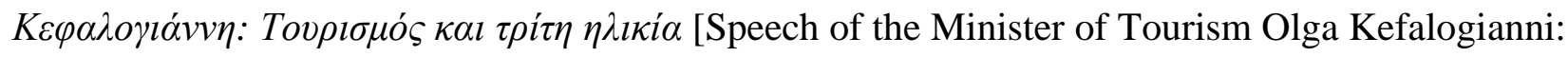
$\begin{array}{llll}\text { Tourism } & \text { and the from }\end{array}$ http://www.mintour.gov.gr/el/PressRoom/PressReleases/?EntityID=7fd170d8-fdfa-4e21-b0ba$\underline{7 \mathrm{a} 9618 \mathrm{cfe} 6 \mathrm{c} 0}$

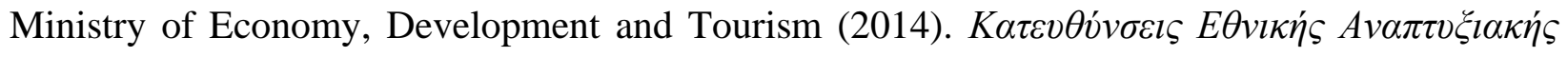

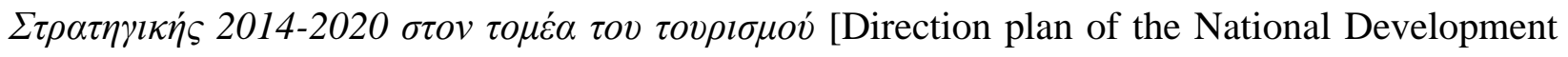
Strategy 2014-2020 for the tourism sector]. Retrieved from http://www.mintour.gov.gr/el/Investments/Espa/Administrationservice/NewProgram20142020/ 
Morgan, N., Pritchard, A., \& Sedgley, D. (2015). Social tourism and well-being in later life. Annals of Tourism Research, 52, 1-15.

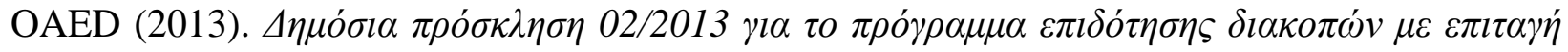

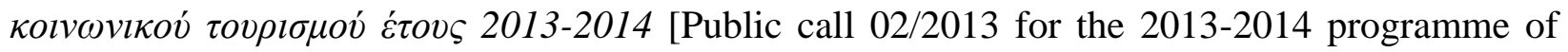
subsidised holidays through social tourism coupons]. Retrieved from http://www.koinonikostourismos.gr/pdfs/dhmosiaproskloaed2013.pdf

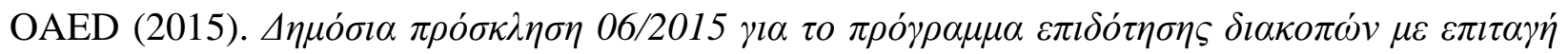

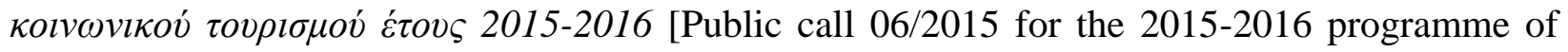
subsidised holidays through social tourism coupons]. Retrieved from http://www.oaed.gr/documents/10195/1224065/dimproskl16.pdf/849a7ffc-43f5-49b8-bf26-

\section{$\underline{\text { 6789da7a2801 }}$}

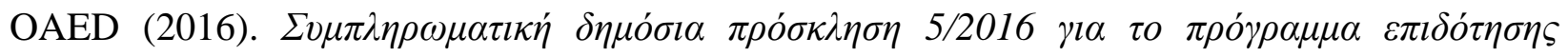

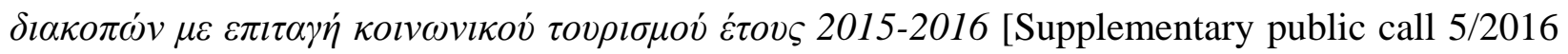
for the 2015-2016 programme of subsidised holidays through social tourism coupons]. Retrieved from http://www.oaed.gr/koinonikos-tourismos-2015-2016

OECD (2001). The DAC Guidelines: Strategies for sustainable development. Retrieved from http://www.oecd.org/dac/environment-development/2669958.pdf

OECD (2011). How's Life? Measuring Well-Being, OECD Publishing.

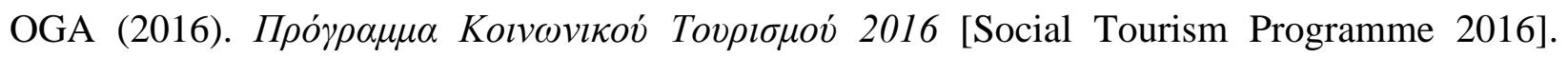
Retrieved from http://www.oga.gr/index.php?pg=estia1

Ryan, C. (2002). Equity, management, power sharing and sustainability - issues of the 'new tourism.' Tourism Management, 23 (1), 17-26. 


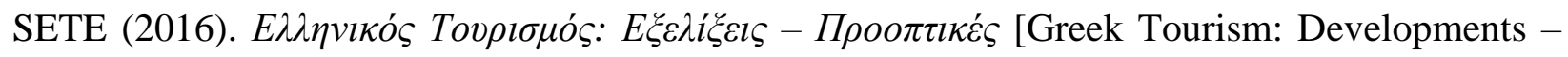
Prospects]. Retrieved from http://sete.gr/media/5444/periodiki-meleti-ellinikos tourismos teyhos-1.pdf

Sharpley, R. (2000). Tourism and sustainable development: Exploring the theoretical divide. Journal of Sustainable Tourism, 8 (1), 1-19.

UN (2010). Sustainable development: From Brundtland to Rio 2012. New York, NY: United Nations.

WCED (1987). Our Common Future. Retrieved from http://www.un-documents.net/our$\underline{\text { common-future.pdf }}$

Woo, E., Kim, H., \& Uysal, M. (2015). Life satisfaction and support for tourism development. Annals of Tourism Research, 50, 84-97. 